\title{
An analysis of the effect of glutethimide on REM density ${ }^{1.2}$
}

CLYDE ALLEN, ANTHONY KALES, Departments of Psychology and Psychiatry and Brain Research Institute, University of Califormia, School of Medicine, Los Angeles, California 90024, and RALPH J. BERGER, Department of Psychology, Crown College, University of California, Santa Cruz, California

A non barbiturate hypnotic, glutethimide (Doriden), was administered to nine normal Ss in either 500 or $1000 \mathrm{mg}$ doses just prior to their bedtime. Various measures of eye movement density during subsequent rapid eye movement (REM) sleep periods showed significant decreases from baseline to drug nights, and increases from baseline and drug nights to drug withdrawal nights. The hypothesis that decreases and increases in the percentage of stage REM sleep (as a function of glutethimide administration and withdrawal, respectively) are accompanied by concomitant decreases and increases in REM densities was supported.

Various studies have indicated that the administration or withdrawal of certain sedatives and hypnotics prior to sleep onset results in a respective decrease or increase in the percentage of time spent in rapid eye movement (REM) sleep ${ }^{3}$ (Kales, Jacobson, Kales, Marusak, \& Hanley, 1967; Oswald, Berger, Jamarillo, Keddie, Olley, \& Plunkett, 1963; Oswald \& Priest, 1965). Oswald et al (1963) found that the hypnotic heptabarbitone also decreased the frequency of rapid eye movements.

In a previous study, the administration of $500 \mathrm{mg}$ of glutethimide (Doriden) on a given night was followed by a marked suppression of REM sleep, and subsequent withdrawal of the drug was followed by a marked rebound in the amount of time spent in REM sleep (Kales, Jacobson, Kales, Marusak, \& Hanley, 1967). A follow-up investigation using $1000 \mathrm{mg}$ doses served to heighten these effects. The records from these studies were then re-analyzed to test the hypothesis that there would be a disproportionate decrease and increase in the number of REMs as a function of drug administration and withdrawal respectively; thus it was expected that REM censities (REMs per unit measurement) would decrease with drug administration and increase with drug withdrawal. That the propensity of REM sleep may always be correlated with the density of REMs is supported by ontogenetic data (Berger \& Meier, 1968; Meier \& Berger, 1965) and studies on the effects of REM sleep deprivation (Ferguson \& Dement, 1967).

Nine Ss were studied. Of these, five were placed in Group 1 (three males, two females) and four in Group 2 (all males). The Ss were screened to eliminate those with any medical or psychiatric disorders, as well as those taking medications or drugs. Each was instructed not to sleep during the day, but to otherwise maintain his usual daytime habits.

All Ss slept on consecutive nights in air-conditioned, sound-attenuated rooms. Continuous all-night recordings were taken of the electroencephalogram (EEG), electromyogram (EMG), and electrooculogram (EOG) on a 16-channel Grass model
IV-C electroencephalograph (Jacobson, Kales, Zweizig, \& Kales, 1965). The EOG used for the scoring of eye movements in this study was derived from an electrode attached lateral to and slightly below the right eye and referred to a supranasion electrode. The gain was $50 \mu \mathrm{V} / \mathrm{cm}$, time-constant $0.3 \mathrm{sec}$, and paper speed $15 \mathrm{~mm} / \mathrm{sec}$.

Ss in Group 1 were administered single, gelatin cansules containing $500 \mathrm{mg}$ of glutethimide or a matching common placebo on each successive night according to the following sequence: P P P D D D P P. After adaptation to the laboratory, Ss in Group 2 were administered a $1000 \mathrm{mg}$ dose of glutethimide in the sequence P D P. Each S received his capsule just before the lights were turned out, then he was allowed to sleep undisturbed. Various ratios of eye movement density (EMD) were then computed from an examination of the REM periods of each $S$. These included mean numbers of: (1) isolated eye movements per minute of REM, (2) bursts per minute of REM, (3) eye movements per REM burst, (4) total eye movements per minute of REM. For the purpose of these calculations, the same eye channel was examined on each record, a deflection being considered as an eye movement only if it exceeded $35 \mu \mathrm{V}$ amplitude from baseline. Consecutive deflections were considered to be separate eye movements if their positive or negative peaks did not occur within $0.3 \mathrm{sec}$. Two or more eye movements were defined as a "burst" if their peaks, positive or negative, occurred within $6 \mathrm{sec}$ of each other; those remaining were "isolated" eye movements. The EMDs on a given night were averaged over all REM periods of that night for each $S$ and group means were then computed. All differences between conditions were tested for significance using Student's t-test.

For Group 1, Nights 3, 4, and 7 were chosen as most representative of baseline, drug, and withdrawal nights, respectively. Table 1 shows the EMD ratios for Group 1. The EMDs on dnig nights tended to be lower than on baseline nights, but were not significantly different. On withdrawal nights, three of the four EMD ratios were greater than on drug nights; the increase in total REMs per minute attaining statistical significance $(p<.05)$. Two of the EMD ratios on the withdrawal night were found to surpass baseline night levels as well as drug night levels. One such increase over baseline, again the mean number of total REMs per minute, was significant $(\mathrm{p}<.025)$.

The EMDs on baseline, drug and withdrawal nights (Nights 1, 2, and 3 , respectively) for Group 2 are shown in Table 2 . Unlike Group 1, Group 2 showed decreases from Night 1 to Night 2, and increases from Night 2 to Night 3 for every EMD measure. The differences in EMD were significant for all measures except for the mean number of eye movements per burst (Table 2).

Although Group 1 on withdrawal nights exhibited higher EMDs than on baseline nights, a similar effect was not observed in Group 2 (Table 2). In fact, the EMDs on withdrawal nights in Group 2 tended to be lower than on baseline nights. It is possible that this unexpected result was caused by a residual drug effect under the higher dosage so that. although the percentage of stage REM

Table 1

EMDs Resulting from the Administration and Withdrawal of $500 \mathrm{mg}$ of Glutethimide (Group 1 )

\begin{tabular}{|c|c|c|c|c|c|c|c|c|c|}
\hline Mean Number & Night 3 & Night 4 & Difference & Night 4 & Night 7 & Difference & Night 3 & Night 7 & Difference \\
\hline $\begin{array}{l}\text { Isolated Eye Movements } \\
\text { per min of REM }\end{array}$ & 0.38 & 0.41 & +0.03 & 0.41 & 0.37 & -0.04 & 0.38 & 0.37 & -0.01 \\
\hline $\begin{array}{l}\text { Bursts } \\
\text { per min of REM }\end{array}$ & 0.94 & 0.91 & -0.03 & 0.91 & 0.94 & +0.03 & 0.94 & 0.94 & 0.00 \\
\hline $\begin{array}{l}\text { Eye Movements } \\
\text { per REM Burst }\end{array}$ & 6.19 & 5.83 & -0.36 & 5.83 & 7.55 & +1.72 & 6.19 & 7.55 & +1.36 \\
\hline $\begin{array}{l}\text { Total Eye Movements } \\
\text { per min of REM }\end{array}$ & 6.20 & 5.89 & -0.31 & 5.89 & 8.73 & $+2.84^{*}$ & 6.20 & 8.73 & $+2.53^{* *}$ \\
\hline
\end{tabular}

$* p<.05$. Student $t$, correlated observations

${ }^{* *} p<.025$, Student $t$, correlated observations 
Table 2

EMDs Resulting from the Administration and Withdrawal of $1000 \mathrm{mg}$ of Glutethimide (Group 2)

\begin{tabular}{|c|c|c|c|c|c|c|c|c|c|}
\hline Mean Number & Night 1 & Night 2 & Difference & Night 2 & Night 3 & Difference & Night 1 & Night 3 & Difference \\
\hline $\begin{array}{l}\text { Isolated Eye Movements } \\
\text { per min of REM }\end{array}$ & 0.60 & 0.22 & $0.38^{* *}$ & 0.22 & 0.46 & $+0.24^{*}$ & 0.60 & 0.46 & -0.14 \\
\hline $\begin{array}{l}\text { Bursts } \\
\text { per min of REM }\end{array}$ & 1.53 & 0.26 & $-1.27 * *$ & 0.26 & 0.90 & $+0.64^{*}$ & 1.53 & 0.90 & -0.63 \\
\hline $\begin{array}{l}\text { Eye Movementsq } \\
\text { per REM Burst }\end{array}$ & 4.79 & 2.47 & -2.32 & 2.47 & 3.96 & +1.49 & 4.79 & 3.96 & $-0.83^{*}$ \\
\hline $\begin{array}{l}\text { Total Eye Movements } \\
\text { per min of REM }\end{array}$ & 7.82 & 2.24 & $-4.58 * *$ & 2.24 & 3.92 & $+1.68^{*}$ & 7.82 & 3.92 & -3.90 \\
\hline
\end{tabular}

$* p<.05$, Student $t$, correlated observations

$* * p<.025$, Student $t$, correlated observations

increased above baseline levels (Kales et al, 1968), recovery from the effect of the drug may have been delayed for the REMs.

The results support the initial hypothesis that glutethimide decreases both the frequency of REMs and the percentage of stage REM, with both measures showing an increase following its withdrawal. These effects were found to be more pronounced when a "double dose" of the sedative was involved. The changes noted with glutethimide administration and withdrawal are similar to those reported with pentobarbital (Wender, Koresko, Gottlieb, \& Feinberg, 1964).

It is speculated that these increases and decreases in eye movement density are accompanied by simultaneous increases and decreases in the "intensity" of the dream experience. This would agree with observations that nightmares are frequently reported subsequent to sedative withdrawal (Kales \& Jacobson, 1967; Oswald \& Priest, 1965).

\section{REFERENCES}

BERGER, R. J., \& MEIER, G. W. Eye movements during sleep and wakefulness in monkeys deprived of patterned vision. Psychophysiology, 1968 , in press. (Abstract)

FERGUSON, J., \& DEMENT, W. C. The effect of variations in total sleep time on the occurrence of rapid eye movement sleep in cats. Electroencephalography \& Clinical Neurophysiology, 1967, 22, 2-10.

JACOBSON, A., KALES, A., ZWEIZIG, J. R., \& KALES, J. Special EEG and EMG techniques for sleep research. American Journal of EEG Technology, $1965,5,5-10$.

KALES, A., \& JACOBSON, A. Mental activity during sleep: Recall studies, somnambulism and effects of rapid eye movement deprivation and drugs.
In Physiological correlates of dreaming, by C. D. Clement, (Ed.), Experimental Neurology, 1967, Suppl. 4, 81-91.

KALES, A., JACOBSON, A., KALES, J. D., MARUSAK, C., \& HANLEY, J. Effects of drugs on sleep (Noludar, Doriden, Nembutal, Chloral Hydrate, Benadryl). Psychophysiology, 1968, 4, 391.

MEIER, G. W., \& BERGER, R. J. Development of sleep and wakefulness patterns in the infant rhesus monkey. Experimental Neurology, 1965, 12, 257-277.

OSWALD, I., BERGER, R. J., JAMARILLO, R. A., KEDDIE, M. G., OLLEY, P. D., \& PLUNKETT, G. B. Melancholia and barbiturates: A controlled EEG body and eye movement study of sleep. British Journal of Psychiatry, 1963, 109, 66-78.

OSWALD, I., \& PRIEST, R. G. Five weeks to escape the sleeping-pill habit. British Journal of Medical Psychology, 1965, 2, 1093-1099.

WENDER, P., KORESKO, R., GOTTLIEB, F., \& FEINBERG, I. Effects of drugs on sleep. Paper presented to the Association for the Psychophysiological Study of Sleep, Palo Alto, California, 1964.

\section{NOTES}

1. Requests for reprints should be addressed to Clyde Allen, Department of Psychiatry, University of California, Los Angeles, Calif. 90024.

2. Study supported in part by NINDB Grant NB-02808, and NIMH Training Grant 5TI MH-6415 of the Brain Research Institute, UCLA School of Medicine. Study also assisted by the UCLA Brain Information Service, a part of the National Information Network of the NINDB and supported under Contract $\mathrm{PH}-43-66-59$.

3. "Stage REM" and "REM sleep" are used interchangeably throughout the paper. 